\title{
Production de bulbes in vitro et de novo à partir de tissus de tiges feuillées florifères de Tulipa gesneriana L, cv Lucky Strike en cours d'élongation : étude histologique
}

\author{
F Chanteloube $1^{\star}, \mathrm{M}$ Tort 2 , JC Courduroux 2 , M Le Nard 1
}

1 INRA, Station d'amélioration de la pomme de terre et des plantes à bulbes, 29260 Ploudaniel;

2 Université Blaise Pascal, laboratoire de physiologie et génétique végétales, 4 rue Ledru, 63038 Clermont-Ferrand, cedex 1 , France

(Reçu le 18 septembre 1992; accepté le 22 décembre 1992)

\begin{abstract}
Résumé - L'obtention de novo de bulbes in vitro est possible chez la tulipe dans un délai de 7-8 mois en utilisant des explants issus de tiges florifères en croissance. Leur ontogenèse a été suivie histologiquement depuis la mise en culture jusqu'à l'obtention des bulbes néoformés. Elle se déroule en 4 grandes étapes résumées de la façon suivante : mise en place d'une "expansion foliacée" d'origine épidermique, formation d'un bourgeon à l'aisselle de cette néoformation, néoformation des racines au niveau du plateau du futur bulbe et bulbification. D'un point de vue morphologique, les bulbes néoformés présentent toutes les conditions requises pour pouvoir donner naissance à des éléments de renouvellement fonctionnels.
\end{abstract}

Tulipa gesneriana L / culture in vitro / bulbes néoformés / histologie

Summary - In vitro neoformation of bulblets from growing floral stem segment of Tulipa gesneriana L, cv Lucky Strike: a histological study. De novo bulblets have been obtained in vitro after 7-8 months using explant discs excised from the growing floral stem of tulip. Their ontogeny was studied histologically, from the beginning of the culture to the neoformation of bulbs. Four important steps have been noted: primary formation of a leaf-like structure induced from epidermal cells, differentiation of an apical bud at the base of this neoformation, neoformation of roots of the future bulblet and bulbification. The morphology of the neoformed bulbs indicated that they would be able to develop normally.

Tulipa gesneriana $L$ /in vitro culture / neoformed bulblet / histology

\section{INTRODUCTION}

Les recherches concernant la micropropagation in vitro de la tulipe se sont développées, depuis quelques années, en France, en GrandeBretagne et au Japon. En effet, le faible coefficient annuel de multiplication (entre 2 et 3 ) de cette plante à bulbes constitue un obstacle important à la diffusion rapide des nouvelles variétés. Une technique de multiplication accélérée permettrait de réduire le délai nécessaire à la commercialisation d'un nouveau cultivar (actuellement 25 ans), et sa maîtrise présenterait un grand intérêt surtout dans le contexte de la création variétale.

Une première série de travaux est basée sur l'utilisation d'explants porteurs d'un ou plusieurs méristèmes au moment de la mise en culture. La méthode consiste à provoquer le développement des méristèmes -inhibés in situ- par des conditions artificielles appropriées. C'est ainsi que Rivière et Muller (1976) parviennent, en mettant en culture des bourgeons végétatifs axillaires du bulbe mère, à atteindre une production d'une dizaine de caïeux par bulbe. Une seconde série de travaux exploite l'aptitude des

* Correspondance et tirés à part 
tissus végétaux à la néoformation de bourgeons. Les premiers résultats positifs sont ceux de Bancilhon (1974) qui obtient des bourgeons néoformés à partir de disques issus de tiges feuillées florifères prélevées dans des bulbes en cours de conservation. Utilisant les mêmes fragments d'organes, mais des conditions expérimentales différentes, Wright et Alderson (1980), dans un premier temps, confirment ces résultats et, dans un deuxième temps, réussissent à provoquer la bulbification in vitro (Alderson et al, 1983a,b; Rice et al, 1983). À partir de fragments d'écailles provenant de bulbes ayant à peine commencé leur développement, Rivière et Muller (1979) parviennent à produire des bourgeons néoformés, puis des bulbes. Des résultats similaires sont obtenus par Nishiuchi $(1979,1980,1982)$ à partir de fragments d'écailles prélevées dans des bulbes en fin de grossissement ou en cours de conservation. Les coefficients de multiplication observés ne sont toutefois pas clairement chiffrés par les auteurs.

Plus récemment, Le Nard (1989) montre que des tissus prélevés sur des tiges feuillées florifères en croissance présentent la potentialité de produire des bourgeons adventifs qui peuvent évoluer en bulbes. De plus, le nombre de ces derniers est nettement supérieur à celui obtenu à partir de tiges feuillées florifères prélevées dans des bulbes en cours de conservation (Le Nard et al, 1987).

En conséquence, les explants de tiges feuillées florifères, dont l'élongation est déjà bien avancée, apparaissent actuellement comme des tissus réactifs; ils constituent sans doute le matériel le plus approprié pour la mise en place de recherches destinées à obtenir les informations indispensables à une meilleure maîtrise de l'organogenèse. Nous avons, à partir de ce matériel, détecté et caractérisé les zones organogènes et décrit les processus histologiques conduisant à la formation de bourgeons adventifs, puis de bulbes.

\section{MATÉRIEL ET MÉTHODES}

Des bulbes de Tulipa gesneriana L, cultivar Lucky Strike, subissent dès leur récolte, un passage d'une semaine à $34^{\circ} \mathrm{C}$ suivi d'un stockage à $20^{\circ} \mathrm{C}$, à l'obscurité. La durée minimale de ce dernier est de 7-8 semaines pour permettre une différenciation totale des organes floraux. Les bulbes subissent ensuite un passage de 9 semaines à $5{ }^{\circ} \mathrm{C}$, nécessaire pour permettre la croissance ultérieure des plantes (Le Nard et
Cohat, 1968). Les bulbes sont alors placés dans de la vermiculite, à $16^{\circ} \mathrm{C}$ et à l'obscurité totale.

Pendant la phase d'élongation rapide, les organes aériens des plantes sont prélevés lorsque le nœud d'insertion de la feuille de base se trouve à environ $45 \mathrm{~mm}$ de la base de la fleur. Après une désinfection de 3 min dans l'éthanol à $70 \%$, suivie de 3 rinçages dans de l'eau stérile, les feuilles sont supprimées, ainsi que la fleur terminale, et la tige feuillée florifère est découpée en disques d'une épaisseur voisine de $1 \mathrm{~mm}$. Ces disques, à raison de 24 par tige feuillée florifère, sont placés, en respectant la polarité, dans des tubes de $25 \times 150 \mathrm{~mm}$, contenant environ $13 \mathrm{ml}$ de milieu. Ce dernier, outre les éléments minéraux de Murashige et Skoog (1962), comprend $500 \mathrm{mg} / \mathrm{l}$ d'hydrolysat de caséine, $200 \mathrm{mg} / \mathrm{l}$ de L-glutamine, $100 \mathrm{mg} / \mathrm{l}$ de myo-inositol, $20 \mathrm{mg} / \mathrm{l}$ de glycine, $10 \mathrm{mg} / \mathrm{l}$ de thiamine, $5 \mathrm{mg} / \mathrm{l}$ d'acide nicotinique, $1 \mathrm{mg} / /$ de pyridoxine $30 \mathrm{~g} / \mathrm{l}$ de saccharose, ainsi que les régulateurs de croissance suivants : acide naphtalène acétique (ANA) 5,3 $\mu \mathrm{mol} . \mathrm{I}^{-1}$, benzylaminopurine (BAP) $4,4 \mu \mathrm{mol} . \mathrm{I}^{-1}$, 2isopentényladénine (2IP) $14 \mu \mathrm{mol} . \mathrm{I}^{-1}$. Le pH du milieu est ajusté à 6,1 avec $\mathrm{KOH} 0,1 \mathrm{~N}$ avant addition de l'agent gélifiant (Satiagel $10 \mathrm{~g} / \mathrm{l}$ ) et autoclavage $\left(15 \mathrm{~min}\right.$ à $120^{\circ} \mathrm{C}$ ). Les cultures sont alors placées à $20^{\circ} \mathrm{C}$, à l'obscurité. Au bout de 2 mois, les explants sont repiqués sur un milieu de base similaire au précédent mais sans régulateurs de croissance et enrichi en saccharose $\left(60 \mathrm{g.l}^{-1}\right)$. Le $\mathrm{pH}$ est ajusté à 5,1 avec $\mathrm{KOH} 0,1 \mathrm{~N}$ avant addition de l'agent gélifiant (Satiagel $10 \mathrm{~g} / \mathrm{l}$ ) et autoclavage. Les cultures sont placées à $5^{\circ} \mathrm{C}$. Après 3 mois, elles sont à nouveau transférées à $20^{\circ} \mathrm{C}$.

Durant la culture in vitro, des prélèvements d'explants sont effectués régulièrement en fonction du stade de développement. Fixés au Chamberlain (formol : $2 \mathrm{ml}$; acide acétique : $1 \mathrm{ml}$; alcool $70 \%: 17 \mathrm{ml}$ ), ils sont inclus dans la paraffine après déshydratation à l'éthanol $100 \%$. Des coupes de $10 \mu \mathrm{m}$ d'épaisseur sont réalisées et colorées à l'hématoxyline de Regaud ou au vert de méthyle pyronine (Brachet, 1953).

\section{RÉSULTATS}

\section{Description d'une coupe transversale d'entre-nœud}

Une coupe transversale pratiquée dans un segment d'entre-nœud qui vient d'être prélevé sur la plante mère montre que la zone superficielle (fig 1) est constituée d'un épiderme recouvert d'une épaisse cuticule et présentant une intense activité mitotique (taux de mitoses : 8,3\%). Sousjacent à cet épiderme, on observe un parenchyme cortical aux contours cellulaires plus ou moins arrondis, ménageant de très nombreux méats et comportant environ 6 assises de cel- 
lules puis un parenchyme périfasciculaire composé de cellules plus petites que les précédentes, aux contours également arrondis, mais moins méatifères. La zone profonde est constituée de faisceaux conducteurs répartis sur 5 ou 6 cercles concentriques (chaque faisceau comportant un massif phloémien externe enserré dans un faisceau xylémien) et d'un parenchyme médullaire.

\section{Mise en place des expansions foliacées}

Quarante huit heures après la mise en culture à $20{ }^{\circ} \mathrm{C}$, le taux de mitoses diminue dans l'épiderme $(8,3 \%$ à $5 \%)$ tandis qu'il reste constant dans le parenchyme cortical $(3,3 \%$ au moment $\mathrm{du}$ prélèvement, $3,1 \%$ après $2 \mathrm{j}$ de culture). Les noyaux des cellules du parenchyme cortical sont sphériques, d'un diamètre moyen de $9 \mu \mathrm{m}$, le RNP (rapport nucléoplasmique) est d'environ $15 \%$; 2 à 4 nucléoles s'individualisent nettement; le cytoplasme apparaît particulièrement dense. Cinq jours environ après la mise en culture, certaines cellules du parenchyme cortical apparaissent comme fortement pyroninophiles et de nombreux cloisonnements périclines sont observés (fig 2). Vers le $10^{\mathrm{e}} \mathrm{j}$ de culture, les caractéristiques observées aux stades précédents s'accentuent : les cloisonnements périclines au sein du parenchyme cortical sont de plus en plus nombreux (fig 3). En outre, la zone périfasciculaire est également le siège de divisions formant un cercle de cellules qui (en coupe transversale) apparaissent petites par rapport aux cellules du parenchyme cortical, et empilées, rappelant ainsi une "zone cambiale» (fig 4). Les cellules du parenchyme médullaire ne se divisent pas ou très peu (dans ce dernier cas, ce sont les cellules les plus périphériques qui se cloisonnent).

Au quinzième jour de culture, toujours à $20^{\circ} \mathrm{C}$, on note une prolifération cellulaire intense au sein du parenchyme cortical avec des cloisonnements périclines, anticlines et obliques. On voit apparaître dans ce tissu néoformé de petits massifs méristématiques présentant plus ou moins l'aspect de nodules. La localisation de ces néoformations semble aléatoire. Elles sont constituées de petites cellules, analogues à celles de points végétatifs, à fort rapport nucléoplasmique (fig 5). Dans le même temps, des divisions périclines sont observées ça et là dans l'épiderme. Le taux de mitoses, qui était de $2,1 \%$ après $5 \mathrm{j}$ de culture, est passé progressivement à une valeur de $31,3 \%$ après 20 jours. Rapidement, les nom- breuses divisions anticlines et périclines de l'épiderme conduisent à la formation d'un groupe de cellules de taille réduite, à cytoplasme dense et noyau volumineux (fig 6); le RNP est alors de $23 \%$. Les mitoses épidermiques donnent ainsi naissance à un massif de cellules (fig 7) à partir duquel va s'organiser la future expansion foliacée. Ce massif méristématique devient alors de plus en plus volumieux; des liaisons procambiales s'établissent entre ce dernier et les tissus conducteurs du parenchyme néoformé sousjacent (fig 8). Progressivement, résultant de nombreuses divisions périclines, des organes en forme de lame aplatie plus ou moins allongée sont mis en place : ce sont les expansions foliacées.

\section{Formation des bourgeons}

La formation des méristèmes gemmaires survient aussi bien à $20{ }^{\circ} \mathrm{C}$ qu'après transfert à $5{ }^{\circ} \mathrm{C}$. Les expansions foliacées continuent leur croissance, présentant l'aspect de feuilles de 5 à $10 \mathrm{~mm}$ de longueur (fig 9). À leur aisselle, on note un début d'activité méristématique se traduisant par l'apparition de cloisonnements périclines internes et formant finalement un massif méristématique (fig 10). Ce dernier, fortement chromophile mais non zoné, constitue rapidement une petite proéminence à l'aisselle de l'expansion foliacée (fig 11). Le méristème médullaire sous-jacent est bien visible. Peu de temps après, le méristème s'entoure d'un primordium d'écaille qui évolue rapidement en une première ébauche d'écaille (fig 12), dont la partie apicale s'allonge (fig 13), tandis que le primordium correspondant à la deuxième écaille surgit (fig 14). Au terme des 3 mois à $5{ }^{\circ} \mathrm{C}$, les expansions foliacées présentent à leur aisselle un bourgeon parfaitement organisé (fig 15).

\section{Mise en place des racines}

Les cellules médullaires sous-apicales ont formé peu à peu un plateau, au niveau duquel sont initiées les racines du futur bulbe; les premières mitoses, conduisant à l'initium radiculaire, s'installent dans la zone périfasciculaire située sous ce plateau. La figure 16 montre les premiers stades d'une ébauche radiculaire : la pyroninophilie des cellules est intense. De nombreux cloisonnements périclines permettent plus tard la 

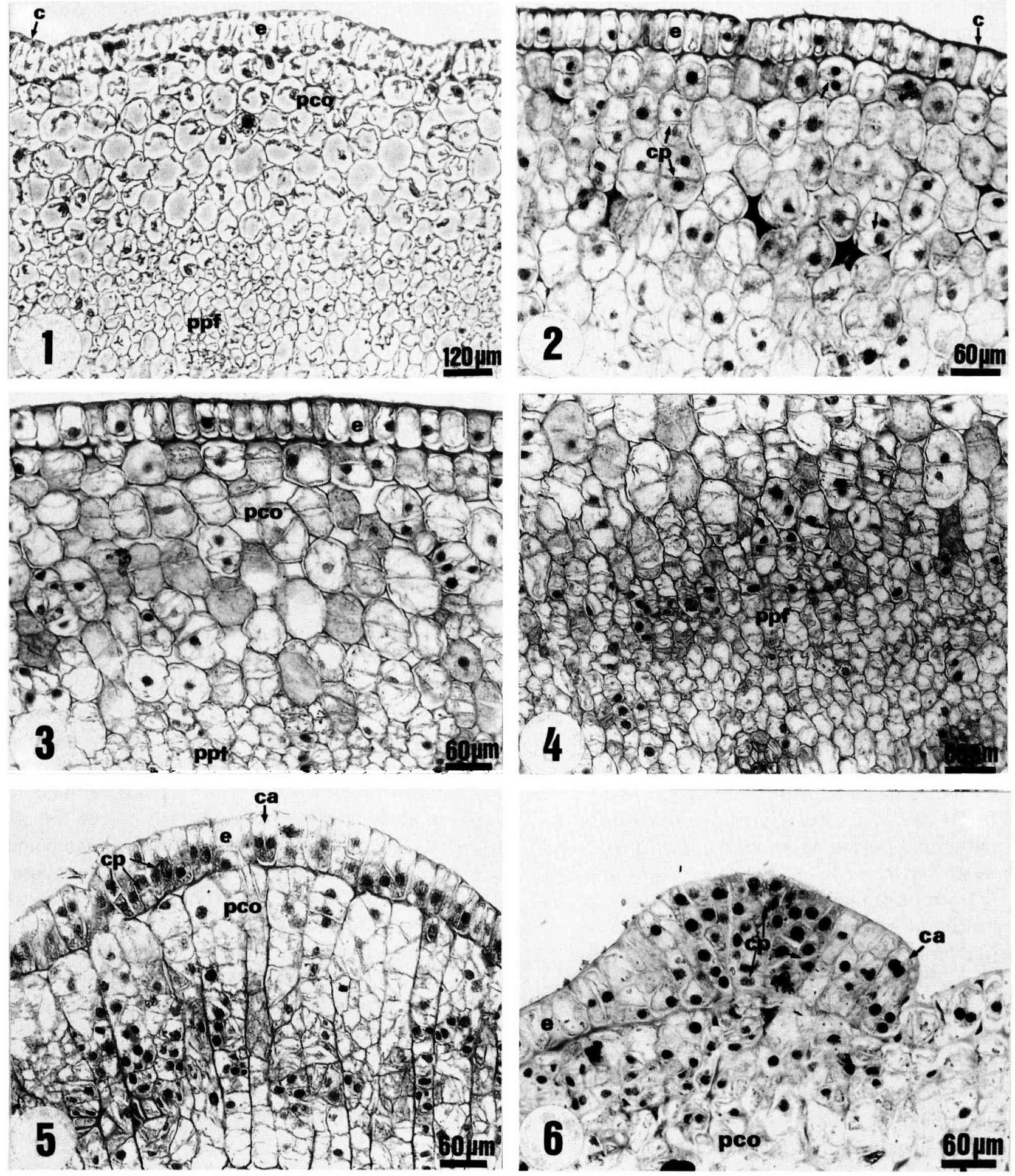

Fig 1. Région corticale d'un entre-nœud de tige feuillée florifère au moment du prélèvement. (c) cuticule; (e) épiderme; (pco) parenchyme cortical; (ppf) parenchyme périfasiculaire. Fig 2. $5^{\mathrm{e}}$ j de culture, nombreux cloisonnements périclines (cp) au sein du parenchyme cortical. Fig 3. $10^{\mathrm{e}}$ j de culture. Activation cellulaire et intensification des cloisonnements au sein du parenchyme cortical. Fig 4. $10^{\mathrm{e}}$ j de culture. Nombreuses divisions dans la zone périfasciulaire donnant à celle-ci l'aspect d'un «cambium». Fig 5. $15^{\ominus} \mathrm{j}$ de cul-

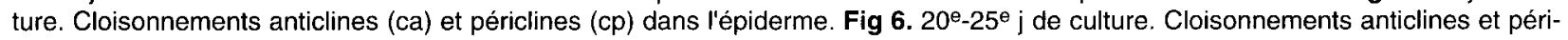
clines dans l'épiderme aboutissant à la formation d'un massif méristématique. 

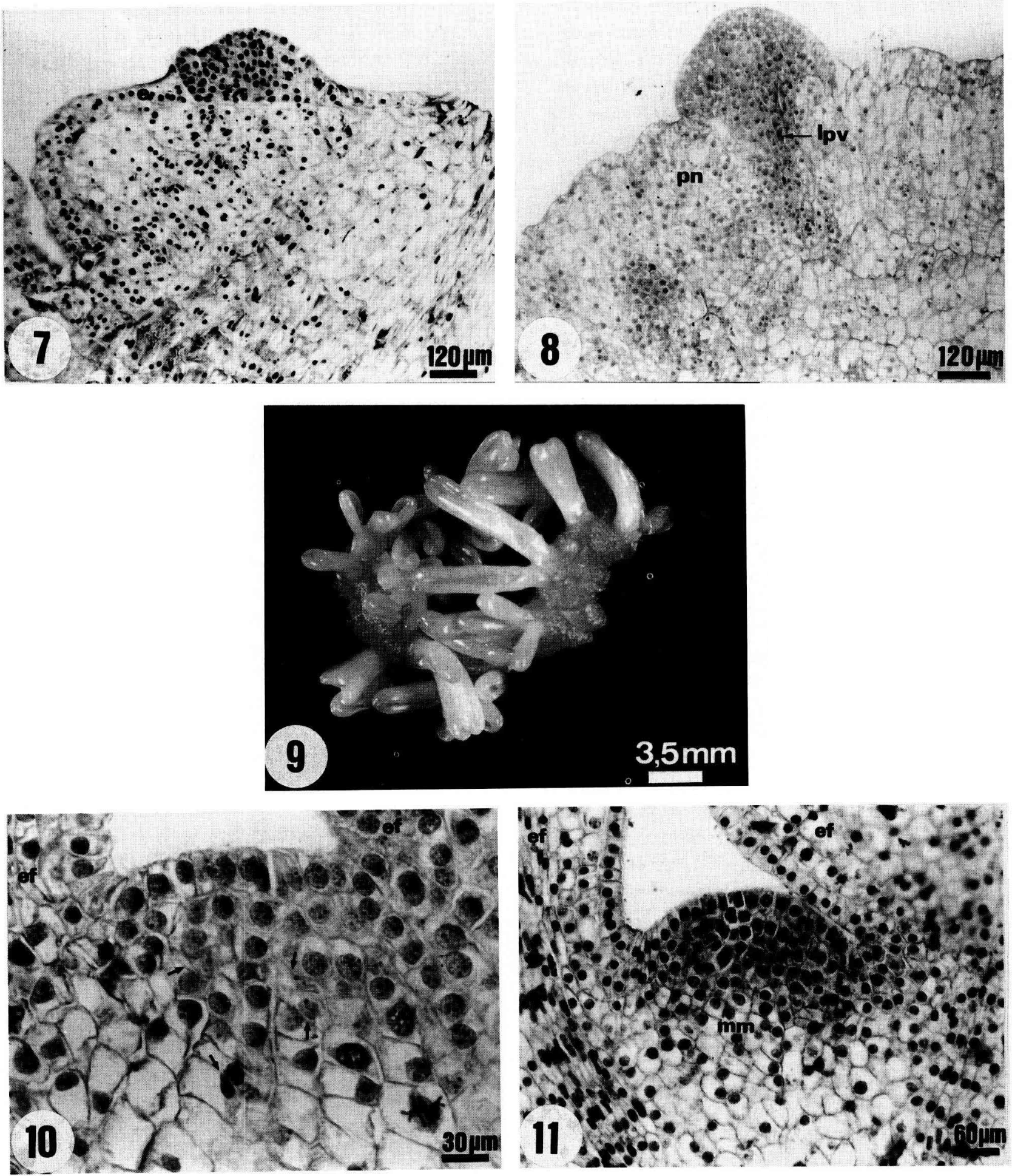

Fig 7. $20^{e}-25^{e} \mathrm{j}$ de culture. Massif méristématique d'origine épidermique. Fig 8. $30^{\mathrm{e}} \mathrm{j}$ de culture. Le massif méristématique devient de plus en plus volumineux, des liaisons provasculaires (Ipv) s'établissent entre ce dernier et le parenchyme néoformé sous-jacent (pn). Fig 9. Macrophotographie d'un explant présentant des expansions foliacées. Fig 10. Petit massif méristématique résultant de cloisonnements périclines (flèche) à la base d'une expansion foliacée (ef). Fig 11. Massif méristématique à la base d'une expansion foliacée ( $\mathrm{mm}$ : méristème médullaire). 
formation de cellules méristématiques disposées en files (fig 17). L'extrémité méristématique prend de l'importance et évolue en une coiffe embryonnaire, tandis que, par ailleurs, se différencie le cylindre central (fig 18). Puis, le méristème acquiert peu à peu sa structure définitive; une région de faible chromaticité, ou centre quiescent, est détectable. La recrudescence des divisions cellulaires rend nettement visible le méristème d'une part, la coiffe racinaire d'autre part (fig 19).

\section{Bulbification}

On peut distinguer dans la bulbification de la tulipe 2 processus : l'induction ou acquisition de l'aptitude à bulbifier et l'explicitation ou extériorisation du phénomène. L'induction de la bulbification nécessite des basses températures et si cette induction est suffisante au départ, l'explicitation de la bulbification se fait de plus en plus rapidement à mesure que la température s'élève (Le Nard, 1980).

Le processus de bulbification induit par le traitement de 3 mois à $5{ }^{\circ} \mathrm{C}$ s'explicite donc lors du transfert à $20^{\circ} \mathrm{C}$. La transformation du bourgeon en bulbe s'effectue progressivement en 6-8 semaines. Dans les primordiums ou ébauches d'écailles entourant l'apex caulinaire, les cellules s'hypertrophient et amorcent un processus de différenciation conduisant à la mise en réserve de grains d'amidon qui s'accumulent à la partie basale des cellules (fig 20). L'expansion foliacée, à l'aisselle de laquelle se développe le petit bulbe, commence à se déshydrater pour former la tunique protectrice externe.

Un petit bulbe, obtenu après 2 mois de culture à $20^{\circ} \mathrm{C}$ (fig 21), est constitué de 1-2 écailles charnues recouvrant le méristème apical qui initie de nouveaux primordiums (fig 22). On constate qu'à la base de l'écaille charnue la plus externe, s'est formé un bourgeon axillaire. Les racines traversent les tissus du plateau en direction de l'épiderme. À ce stade, le jeune bulbe obtenu in vitro a une apparence tout à fait comparable à celle d'un jeune bulbe issu de semis (fig 23) : tunique protectrice externe, écailles charnues, réserves amylifères, racines.

\section{DISCUSSION ET CONCLUSION}

À l'issue de leurs recherches sur le comportement in vitro de fragments de tiges feuillées flori- fères, cv Merry Widow, Wright et Alderson (1980) avaient conclu que l'obtention d'un bourgeonnement adventif n'était plus possible à partir du moment où les explants provenaient de tiges dont l'élongation rapide avait commencé. En accord avec Le Nard (1989), nous démontrons que l'obtention de bulbes in vitro est possible chez la tulipe, cv Lucky Strike, dans un délai de 7-8 mois en utilisant des explants issus de tiges feuillées florifères en croissance. L'utilisation de ce type de matériel présente de nombreux avantages : à la mise à disposition d'une plus grande quantité de tissus (24 explants minimum par tige) s'ajoute la facilité de prélèvement; de plus, il n'est pas nécessaire de détruire le bulbe, ce qui permet la sauvegarde des bulbes fils. Comme dans le cas de culture de tiges feuillées florifères prélevées dans des bulbes en cours de conservation (Le Nard et al, 1987; Baker, 1989; Wright et Alderson, 1980) ou dans le cas de fragments d'écailles (Nishiuchi, 1979; Rivière et Muller, 1979), la formation de ces bulbes passe, dans la majorité des cas, par la mise en place de structures particulières que nous avons appelés «expansions foliacées».

La mise en culture d'explants issus de tiges feuillées florifères de tulipe en croissance, cultivar "Lucky Strike", provoque dans un premier temps une activation cellulaire mitotique du parenchyme cortical sous-jacent. Cette activation précoce pourrait résulter d'une part de l'interruption des corrélations avec la plante mère et d'autre part, d'une réaction de cicatrisation due à l'effet de la blessure. Ce qui est remarquable, c'est que l'activation cellulaire du parenchyme cortical se poursuit jusqu'aux environs du $15^{\mathrm{e}}$ jour, aboutissant à la formation de petits nodules méristématiques localisés de façon apparemment aléatoire au sein du parenchyme néoformé. D'après nos observations, il semblerait que ce phénomène précède de quelques jours l'apparition dans l'épiderme des premières divisions périclines annonciatrices de l'initiation des expansions foliacées; puis, au fur et à mesure du développement de ces dernières, les nodules perdent peu à peu leur état méristématique. La mise en place de ces nodules méristématiques dans le parenchyme cortical néoformé pourrait peut-être présenter un intérêt pour l'étude d'un passage d'un programme non organogénétique pour ce tissu à un programme organogénétique. Chez Torenia fournieri, une étude physiologique menée par Chlyah (1974a) démontre parfaitement qu'une perturbation de l'équilibre des corrélations existant entre les divers tissus du seg- 

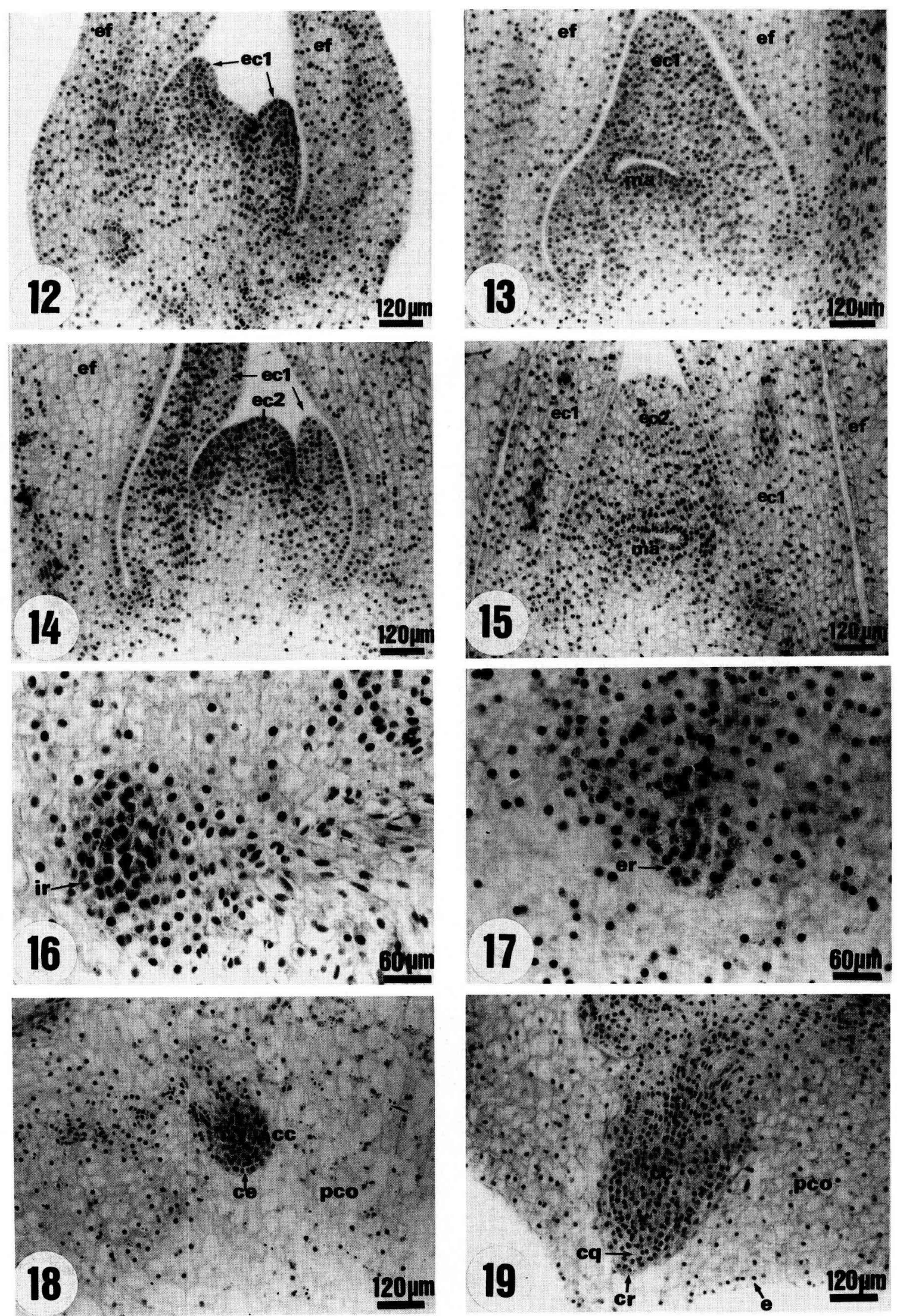

Fig 12. Surrection de la première ébauche d'écailles (ec1) à la base de l'expansion foliacée (ef). Fig 13. L'écaille ec1 entoure complètement le méristème apical (ma) du bourgeon. Fig 14. Développement de l'écaille ec1 et apparition du primordium d'écaille ec2. Fig 15. Jeune bourgeon. les 2 premières écailles $\mathrm{ec}_{1}, \mathrm{ec}_{2}$ recouvrent complètement le méristème apical. Fig 16. Premières cellules d'un initium racinaire au niveau de la zone périfasciculaire. Fig 17. Stade ultérieur montrant l'organisation d'une ébauche racinaire (er). Fig 18. Racine avec coiffe embryonnaire (ce) et cylindre central (cc) traversant le parenchyme cortical (pco) en direction de l'épiderme. Fig 19. Stade ultérieur : racine avec cylindre central (cc), coiffe racinaire (cr) et centre quiescent (cq). 

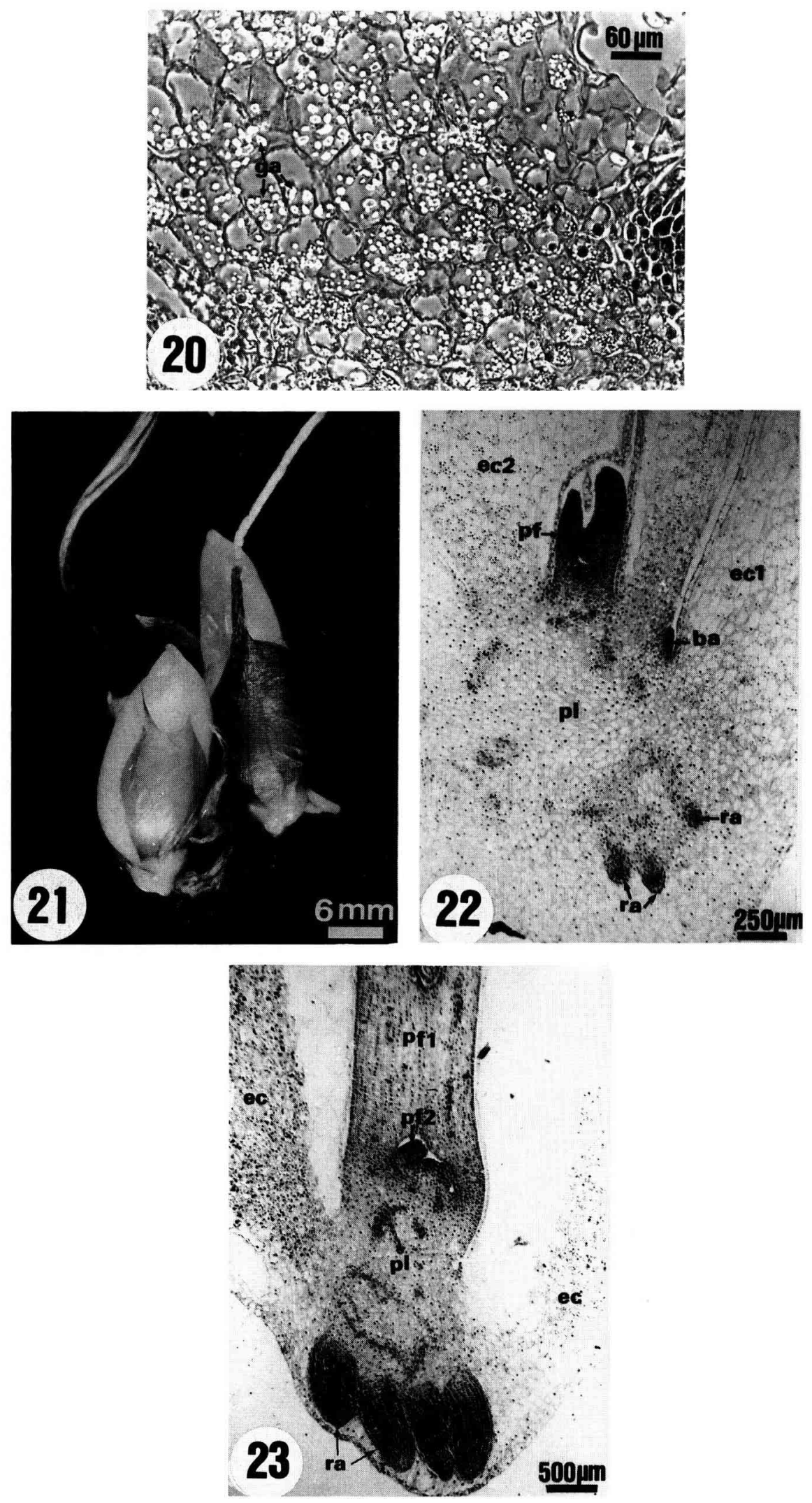

Fig 20. Accumulation de grains d'amidon (ga) au pôle basal des cellules d'une ébauche d'écaille charnue d'un bulbe néoformé. Fig 21. Macrophotographie de bulbes obtenus in vitro. Fig 22. Section longitudinale axiale d'un bulbe obtenu in vitro (ec1, ec2) écailles charnues; (pf) primordium foliaire; (ma) méristème apical; ( $\mathrm{pl}$ ) plateau; (ba) bourgeon axillaire; (ra) racine. Fig 23. Jeune bulbe issu de semis (pf1) pousse feuillée; (pf2) primordium écailleux. 
ment entre-nœud, associée à un apport adéquat de substances de croissance, permet de révéler les potentialités latentes chez des tissus apparemment dépourvus d'aptitude organogène au sein du segment d'entre-nœud considéré dans son ensemble. Ces observations indiquent donc qu'il peut être intéressant de séparer les tissus les uns des autres au moment de la mise en culture afin de déterminer le rôle des corrélations intertissulaires dans l'expression de la capacité organogénétique.

Dans la majorité des cas de bourgeonnement in vitro, il apparaît que, en présence ou non de régulateurs de croissance, le tissu épidermique, ou sous-épidermique joue un rôle primordial, soit dans la mise en œuvre immédiate d'un programme mitotique aboutissant à la mise en place des bourgeons, soit dans la formation d'un cal dont la compétence est révélée plus tardivement. Dans le cas de néoformation directe, les exemples d'activation superficielle épidermique ou sous-épidermique, conduisant au bourgeonnement sont nombreux, soit à partir d'embryons (Picea abies: Von Arnold et al, 1988), soit à partir de cotylédons (sapin de Douglas : Cheah et Cheng, 1978), soit à partir de segments d'entrenœud (Torenia Fournieri : Chlyah, 1974b), soit à partir de tige (Lis hybride: Bigot, 1974) ou d'écaille de bulbe (oignon : Kahane, 1990). La tulipe n'échappe pas à cette règle : l'origine épidermique des expansions foliacées est mise en évidence, ce qui, par ailleurs, permet de confirmer les observations réalisées par Wright et Alderson (1980). II est toutefois intéressant de noter que chez la tulipe in vitro, l'assise ayant la capacité de former des bourgeons dépend de l'organe: en utilisant comme explants des écailles du bulbe fils principal, Rivière et Muller (1979) démontrent que le bourgeonnement débute sous l'épiderme interne.

Le suivi histologique de la mise en place des expansions foliacées laisse apparaître que, sur un explant réactif donné, l'épiderme ne présente pas de zone privilégiée douée de capacité organogène particulière et que, comme chez Torenia fournieri (Chlyah, 1974c) les centres d'initiation de ces néoformations sont localisés en des points apparemment quelconques de l'épiderme. Cependant, il ne nous a pas été possible de déterminer avec les méthodes d'étude classiques, le nombre de cellules épidermiques participant à la formation de l'expansion foliacée.

Le bourgeon apical se met en place à la base de l'expansion foliacée. Ce résultat corrobore les observations de Rivière et Muller (1979). De même, Rice et al (1983) définissent 2 étapes principales lors de la production de bulbes in vitro : I'initiation de «pousses» à partir de la souche cellulaire épidermique, suivie de la mise en place d'un primordium bulbeux à la base de chaque "pousse». Le rôle joué par le changement de milieu et par l'exposition aux basses températures ne semble pas décisif sur la formation de ce bourgeon; ce dernier peut se mettre en place indifféremment à $20^{\circ} \mathrm{C}$ ou à $5{ }^{\circ} \mathrm{C}$, puis les racines du futur bulbe sont initiées dans les tissus du plateau.

$\mathrm{Si}$ les basses températures sont indispensables à l'induction de la bulbification, l'explicitation, quant à elle, se fait de plus en plus rapidement à mesure que la température s'élève (Le Nard, 1980). Les bourgeons sont donc transférés à $20^{\circ} \mathrm{C}$, toujours sur milieu dépourvu de régulateurs de croissance. II a été montré, en effet (Nishiuchi, 1979) que les cytokinines apportées dans le milieu de culture, si elles sont indispensables dans un premier temps à l'initiation des expansions foliacées, pourraient par la suite avoir une action inhibitrice sur l'élaboration et l'organisation du primordium bulbeux. De la même manière, dans le cas d'organogenèse adventive à partir d'embryons, Aubert et al (1986) constatent que si le passage des cultures au froid est indispensable pour la bulbification, le maintien des régulateurs de croissance dans le milieu inhibe complètement le phénomène; toutefois, le transfert sur un milieu dépourvu de régulateurs peut se faire avant ou après le traitement aux basses températures. L'aspect morphologique des bulbes néoformés in vitro est encourageant en vue d'une éventuelle exploitation de ce mode de multiplication. Ils présentent toutes les caractéristiques structurales requises pour pouvoir, une fois plantés en terre, donner naissance à des éléments de renouvellement fonctionnels et assurer un développement normal.

Toutefois, il peut exister une variabilité de réaction des génotypes à la multiplication in vitro (Le Nard et al, 1987; Le Nard, 1989) et les résultats obtenus avec un génotype ne seront pas nécessairement transposables à d'autres sans modifications. En conséquence, pour pouvoir améliorer la production de bulbes in vitro, les recherches doivent être poursuivies dans le but :

- de vérifier que la technique est applicable à une large gamme de génotypes,

- d'augmenter le coefficient de multiplication in vitro, puisqu'il apparaît qu'une augmentation du 
nombre de bulbes viables passe avant tout par une augmentation du nombre de bourgeons aptes à produire ces bulbes,

- de compléter l'étude de l'influence des conditions de culture (concentration en saccharose ou qualité de la lumière) qui peuvent, comme dans le cas de l'oignon (Kahane, 1990) conditionner le processus de bulbification.

\section{REMERCIEMENTS}

Ce travail a été soutenu par une allocation de recherche de l'Institut national de la recherche agronomique (INRA) et du Comité national interprofessionnel de l'horticulture $(\mathrm{CNIH})$. Les auteurs remercient D Marcon pour la réalisation des photographies.

\section{RÉFÉRENCES}

Alderson PG, Rice RD, Wright NA (1983a) Towards the propagation of tulip in vitro. Acta Hortic 131, 3947

Alderson PG, Rice RD, Wright NA (1983b) The potential for propagating tulips through tissue culture. The Plant Propagator 29, 4, 10-13

Aubert B, Weber G, Dorion N, Le Nard M, Bigot C (1986) Étude préliminaire sur l'organogenèse adventive à partir d'embryons de tulipe cultivés in vitro (Tulipa gesneriana L). Can J Bot 64, 1837-1842

Baker C (1989) Cultural factors affecting in vitro meristematic development of tulip (Tulipa gesneriana L). PhD thesis. University of Minnesota. St Paul, MN

Bancilhon L (1974) Premiers essais de multiplication végétative en culture in vitro chez Tulipa gesneriana $\mathrm{L}$ cultivar «Paul Richter» (Liliacée). CR Séances Acad Sci Paris, Série D, t 279, 983-986

Bigot C (1974) Comparaison des aptitudes pour le bourgeonnement de tissus superficiels et de tissus profonds cultivés in vitro. Cas de la tige d'un lis hybride, cultivar Enchantment. CR Séances Acad Sci Paris, Série D, t 278, 1027-1030

Brachet $J$ (1953) The use of basic dyes and ribonuclease for the cytochemical detection of ribonucleic acid. Quart J Microscop Sci 94, 1-10

Cheah KT, Cheng TY (1978) Histological analysis of adventitious bud formation in cultured Douglas fir cotyledon. Am J Bot 65, 8, 845-849

Chlyah H (1974a) Inter-tissue correlations in organ fragments. Organogenetic capacity of tissues excised from stem segments of Torenia fournieri Lind cultured separately in vitro. Plant Physiol 54, 341-348

Chlyah H (1974b) Étude histologique de la néoformation de méristèmes caulinaires et radiculaires à partir de segments d'entre nœud de Torenia fournieri cultivés in vitro. $J$ Exp Bot 39, 473-476
Chlyah H (1974c) Formation and propagation of cell division-centers in the epidermal layer of internodal segments of Torenia fournieri grown in vitro. Simultaneous surface observations of all the epidermal cells. Can J Bot 52, 867-872

Kahane $\mathrm{R}$ (1990) Multiplication et bulbification in vitro d'Allium cepa $L$ en vue de l'amélioration de la variété d'oignon De Mulhouse-type Auxonne. Thèse de Doctorat, Université de Dijon, $127 p$

Le Nard M (1980) Influence de différents traitements thermiques sur l'intensité de l'induction de la bulbification et sa suppression chez le bulbe de Tulipe. Ann Amélior Plant 30 (4), 455-468

Le Nard M (1989) Obtention d'un bourgeonnement adventif par la culture in vitro de fragments de hampes florales prélevées chez des Tulipes (Tulipa gesneriana L) en croissance. CR Séances Acad Sci Paris, t 308, Série III, 389-394

Le Nard M, Cohat J (1968) Influence des températures de conservation des bulbes sur l'élongation, la floraison et la bulbification de la tulipe (Tulipa gesneriana L). Ann Amélior Plant 18, 181-215

Le Nard M, Ducommun C, Weber G, Dorion N, Bigot $C$ (1987) Observations sur la multiplication in vitro de la tulipe (Tulipa gesneriana L) à partir de hampes florales prélevées chez des bulbes en cours de conservation. Agronomie 7, 5, 321-329

Murashige T, Skoog F (1962) A revised medium for rapid growth and bioassay with tobacco cultures. Physiol Plant 15, 473-497

Nishiuchi Y (1979) Studies on vegetative propagation of tulip. II. Formation and development of adventitious buds in the excised scale culture in vitro. $J$ Jpn Soc Hortic Sci 48, 1, 99-105

Nishiuchi $Y$ (1980) Studies on vegetative propagation of tulip. IV. Regeneration of bulblets in bulb scale segments cultured in vitro. J Jpn Soc Hortic Sci 49 , 2, 235-240

Nishiuchi $Y$ (1982) Studies on multiplication of tulip bulb by tissue culture method. I Hokkaido Univ Educ (Section IIB) 33, 1, 49-65 (Jap)

Rice RD, Alderson PG, Wright NA (1983) Induction of bulbing of tulip shoots in vitro. Sci Hortic 20, 377390

Rivière S, Muller JF (1976) La multiplication végétative de la Tulipa gesneriana L, cultivar "Paul Richter», par la culture in vitro des bourgeons axillaires des écailles. CR Séances Acad Sci Paris, t 282, Série D 533-536

Rivière S, Muller JF (1979) Étude du bourgeonnement in vitro de l'écaille du bulbe de tulipe. Can J Bot 57 , 19, 1986-1993

Von Arnold S, Alsterborg E, Walles B (1988) Micromorphological studies of adventitious bud formation on Picea abies embryos treated with cytokinin. Physiol Plant 72, 248-256

Wright NA, Alderson PG (1980) The growth of tulip tissues in vitro. Acta Hortic 109, 263-270 